\title{
A ELABORAÇÃO DE MATERIAL DIDÁTICO UTILIZANDO O H5P: possibilidades para o ensino de História ${ }^{1}$
}

\author{
Fernanda Bassani \\ Universidade Tecnológica Federal do Paraná (UTFPR) \\ nanda.bassanicruz@gmail.com

\begin{abstract}
Hércules Alves de Oliveira Junior Universidade Tecnológica Federal do Paraná (UTFPR) hercules@utfpr.edu.br
\end{abstract}

Romeu Miqueias Szmoski Universidade Tecnológica Federal do Paraná (UTFPR) rmszmoski@gmail.com

Hernani Batista da Cruz Universidade Tecnológica Federal do Paraná (UTFPR) hernanibc@gmail.com

\section{RESUMO}

A utilização das Tecnologias da Informação e Comunicação - TICs em cursos nas modalidades presencial e a distância é recorrente. Com estes recursos, é possível a elaboração de um material didático mais atrativo; com um design instrucional/ educacional bem estruturado, faz com que o conteúdo proposto tenha um melhor aproveitamento na aprendizagem. O objetivo deste trabalho é apresentar o H5P (HTML 5 Package), um plugin que pode ser utilizado no Moodle, Word Press e Drupal, sendo ele totalmente gratuito. Com essa ferramenta, você pode criar materiais com conteúdos mais elaborados, interativos e gamificar suas atividades. $O$ texto tem por base a literatura que aborda questões de gamificação, apresentada por Mattar; Design instrucional, abordada por Filatro e a aprendizagem significativa de Ausubel. Num primeiro momento, é apresentado o H5P; na sequência, as possibilidades de apresentação de conteúdo e atividades a partir deste recurso com os métodos mais adequados segundo o Design instrucional; e por fim, aponta as aplicações desta ferramenta para o ensino de História. O material elaborado e as atividades foram inseridos em um curso de Licenciatura em História de uma Universidade pública. Os resultados são parciais, entretanto obtivemos o feedback positivo dos acadêmicos num primeiro semestre de aplicação, onde os relatos apontam um melhor aprendizado da aplicação de atividades em diferentes formatos.

Palavras-chave: REAS. Tecnologias para Educação. H5P.

${ }^{1}$ Este artigo é a versão expandida de uma comunicação oral apresentada no VII Simpósio de Educação Inclusiva e Adaptações/ V Simpósio Internacional de Educação a Distância. São Paulo, UNESP, 2019. 


\title{
PREPARING TECHING MATERIAL USING THE H5P: \\ possibilities for teaching History
}

\begin{abstract}
The use of Information and Communication Technologies - ICTs in in-classroom and distance learning courses is recurrent. With these resources it is possible to develop more compelling teaching material; with a well structured instructional / educational design, it makes the proposed content better suited for learning. The objective of this paper is to present H5P (HTML 5 Package), a plugin that can be used in Moodle, WordPress and Drupal, completely free. With it you can create materials with more elaborate, interactive content and gamify your activities. The text is based on the literature that addresses issues of gamification presented by Mattar, instructional design by Filatro and the meaningful learning of Ausubel. At first the H5P is presented; following with the possibilities of presentation of content and activities using this resource with the most suitable methods, according to instructional design; and finally, it points out the applications of this tool for the teaching of History. The elaborated material and activities were inserted in a degree course in History of a public university. The results are partial, however it was already possible to obtain in the first semester a positive feedback from the academics, where reports pointed that activities in different formats allowed a better learning.
\end{abstract}

Keywords: REAS. Technologies for Education. H5P.

\section{LA ELABORACIÓN DE MATERIAL DE ENSEÑANZA CON H5P: posibilidades para la enseñanza de Historia}

\section{RESUMEN}

El uso de las tecnologías de la información y la comunicación: las TIC en los cursos en el aula y la educación a distancia es recurriente. Con estos recursos es posible desarrollar material didáctico más atractivo; con un diseño educativo / educativo bien estructurado, hace que el contenido propuesto tenga un mejor uso en el aprendizaje. El objetivo de este trabajo es presentar el H5P (paquete HTML 5), un complemento que se puede utilizar en Moodle, WordPress y Drupal, y totalmente gratuito. Con él usted puede crear materiales con contenido más elaborado e interactivo y gamificar sus actividades. El texto se basa en la literatura que aborda cuestiones de gamificación presentado por Mattar), diseño instruccional por Filatro y el aprendizaje significativo del Ausubel. Al principio, se presenta H5P; en la secuencia, las posibilidades de presentar contenido y actividades de este recurso con los métodos más apropriados, de acuerdo 
con el diseño instruccional; y finalmente, señalar las aplicaciones de esta herramienta para la enseñanza de la historia. El material y las actividades se incluyeron en un curso de Licenciatura en Historia en una universidad pública. Los resultados son parciales, sin embargo, ya fue posible obtener comentarios positivos de los académicos en el primer semestre, donde los informes señalaron que con las actividades en diferentes formatos, permitió un mejor aprendizaje.

Palabras clave: REAS. Tecnologías para la educación. H5P.

\section{INTRODUÇÃO}

As Tecnologias da Informação e Comunicação (TICs) vem ganhando espaço no meio educacional e é crescente a diversidade de recursos que auxiliam na elaboração de um bom material didático. O professor, antes considerado o único detentor do conhecimento, passa a ser um mediador, guiando os alunos pelos conceitos e práticas. O termo blended learning, abordado por Trevisani et al. (2015), surge nesse contexto; também conhecido por ensino híbrido, é uma abordagem pedagógica que tende a combinar o ensino presencial com o ensino a distância por meio das TICs. Com os recursos digitais disponíveis, é possível elaborar aulas interativas, atividades de aprendizagem baseadas em Resolução de Problemas - PBL ou Baseada em Projetos - ABP, entre outras possibilidades.

Um dos recursos digitais que vem apoiando as estratégias pedagógicas são as plataformas virtuais, onde os professores inserem materiais didáticos em uma sala de aula virtual e, no momento em que o aluno achar oportuno, ele realiza seus estudos. A interação com o professor pode ocorrer de forma síncrona, por meio de webconferências e chats, ou de forma assíncrona, através de e-mail ou fóruns. Entretanto, no momento que estamos enfrentando a pandemia do vírus COVID-19, escolas presenciais estão adotando os Ambientes Virtuais de Aprendizagem como auxílio no processo de ensino e aprendizagem de seus alunos.

Uma plataforma mundialmente conhecida é o Moodle (do inglês, Modular Object Oriented Dynamic Learning Environment), um software livre que possibilita a aprendizagem em uma plataforma digital. Sua utilização permite o ensino híbrido e a inserção de conteúdo didático; proporciona também certa comodidade, tratando-se do acesso, que pode ocorrer em qualquer momento e de qualquer local com acesso à internet e até em dispositivos móveis como celulares smartphones. Também expande as estratégias de aprendizado e fornece meios para o aprimoramento de métodos para o ensino.

O H5P é uma abreviação de HTML 5 Package, um dos principais plugins que o Moodle disponibiliza para apresentação de conteúdo interativo e de atividades 
mais atrativas para os alunos. Por ser uma estrutura de elaboração de conteúdo colaborativa, ele pode ser utilizado além do Moodle, em diversos ambientes, como no Word Press, Canvas, Drupal e outros.

O desenho do conteúdo das atividades deve ser pensado de forma criteriosa para atender aos alunos que possuam perfis muito ecléticos, pois os estilos de aprendizagem em uma mesma turma são diferentes.

Inserir características do cotidiano desses alunos em meio ao conteúdo de aula, como jogos, pode tornar o aprendizado mais atrativo. Isso já é realizado nas aulas presenciais e é possível inserir na modalidade a distância, com o uso dos Ambientes Virtuais de Aprendizagem.

Com o movimento REAS - Recursos Educacionais Abertos, muito material didático de excelente qualidade está disponível para ser utilizado, remixado e compartilhado.

\section{OBJETIVO}

É importante compreender que as plataformas digitais não são repositórios de materiais didáticos, há que se ter bom senso no momento da escolha desses materiais e a melhor forma de apresentar esse conteúdo e construir atividades avaliativas.

O objetivo do trabalho é apresentar o H5P, uma ferramenta com diversas possibilidades de interação, seja em atividades presenciais ou à distância; descrever as opções de atividades ou apresentações de conteúdo e indicar alternativas para aplicações desta ferramenta no ensino de História.

\section{FUNDAMENTAÇÃO}

Utilizar diferentes métodos/recursos na sala de aula é um grande desafio, sabemos das limitações de muitas escolas. Até mesmo na educação à distância, se o aluno reside em uma área onde a internet não tem alcance e a plataforma possui muitos recursos que demandam de uma alta resolução, infelizmente o conteúdo não "abre".

A transformação de um conteúdo enfadonho para um conteúdo atrativo e interativo deve ser bem planejada e muitos pontos precisam ser levados em consideração e o design instrucional pode auxiliar nessa tarefa.

O design instrucional ou educacional surge na Segunda Guerra Mundial com o intuito de capacitar os soldados que estavam nos campos de batalha e vai se aperfeiçoando e com todas as mudanças que o setor educacional vem sofrendo. Essa prática passa a fazer parte de diversos setores, com a finalidade de aperfeiçoar o material didático e desenvolver a melhor forma de aplicar os inúmeros recursos disponíveis. 
Segundo Filatro $(2008$, p. 3)

Definimos design instrucional como a ação intencional e sistemática de ensino que envolve o planejamento, o desenvolvimento e a aplicação de métodos, técnicas, atividades, materiais, eventos e produtos educacionais em situações didáticas específicas, a fim de promover, a partir dos princípios de aprendizagem e instrução conhecidos, a aprendizagem humana.

O processo de trabalho do designer instrucional/educacional passa por cinco fases: análise, design, desenvolvimento, implementação e avaliação; todas essas fases são primordiais para a elaboração de um material didático de qualidade.

A possibilidade de gamificar conteúdos e atividades atrai alunos dos mais diversos níveis de ensino e faixa etária. Para Mattar (2010, p. 31)

È uma ilusão imaginar que apenas jovens jogam games hoje: pessoas de diversas faixas etárias - incluindo, por exemplo, diretores de empresas - também jogam. Por isso, os métodos tradicionais de ensino não conseguem mais envolver os alunos em nenhum nível, nem mesmo na educação on-line.

Se jogos são tão divertidos, vamos inseri-los no conteúdo didático, assim deixamos a aula mais divertida e interessante.

Ao pensarmos no processo de aprendizagem, compartilhamos das ideias de Ausubel (1980, p. 34), quando o mesmo define que aprendizagem significativa "são as ideias expressas simbolicamente [e que] são relacionadas às informações previamente adquiridas pelo aluno através de uma relação não arbitrária e substantiva". Dessa forma, uma aprendizagem só será significativa se o estudante conseguir associar uma nova informação a outra já existente na sua estrutura cognitiva.

\section{METODOLOGIA}

A pesquisa procurou apresentar conteúdos e atividades com um novo design, dentro do Ambiente Virtual de Aprendizagem - AVA, do Moodle, de uma Universidade pública para alunos do curso de Licenciatura em História.

Como recurso, utilizamos o $\mathrm{H} 5 \mathrm{P}$, um plugin que está disponível no Moodle e que também pode ser encontrado no Word Press, Drupal e outros. É totalmente gratuito. Você pode criar com ele materiais com conteúdos mais elaborados, interativos e gamificar suas atividades.

Há um site próprio https://www.h5p.org/, onde é possível o usuário se cadastrar, utilizar os modelos disponíveis de configuração e criar seus próprios conteúdos, tudo de forma livre e gratuita. Todo o material produzido fica no perfil do usuário e disponível para qualquer pessoa visualizar. 
São ao todo 43 tipos diferentes de apresentar o conteúdo e realizar atividades interativas. Este conteúdo está dividido em jogos, questões, mídia social e com o uso de recursos multimídia, como mostra a imagem a seguir.

Figura 1 - Conteúdo H5P.

Tipos de Conteúdo

ver tudo Jogos Multimidia Questões Mídia social
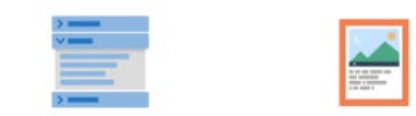

Acordeão

Criar itens expansiveis empilhados

$$
\text { Agamotto }
$$

Crie uma sequência de

imagens que mudam

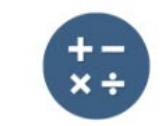

Aritmética Quiz

Criar testes aritméticos

com base no tempo

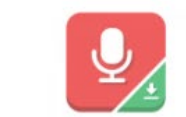

Gravador de áudio

Crie uma gravação de

áudio

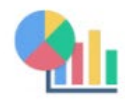

Gráfico

Gere rapidamente

gráficos de barras e de

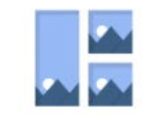

Colagem

Crie uma colagem de várias imagens

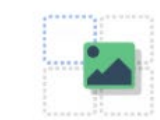

Arrastar e Soltar Crie tarefas de arrastar e soltar com imagens

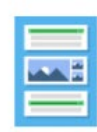

Coluna

Layout da coluna para o conteúdo H5P

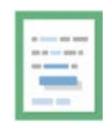

Arraste as palavras Crie tarefas de arrastar e soltar baseadas em

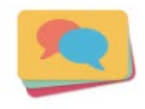

Cartões de Diálogo Crie cartões giratórios baseados em texto

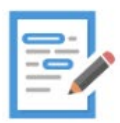

Redação

Criar ensaio com feedback instantâneo

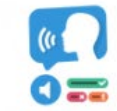

Ditado

Crie um ditado com feedback instantâneo

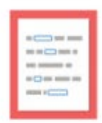

Preencher os espa... Crie uma tarefa com palavras ausentes em

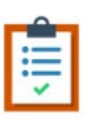

Ferramenta de Doc... Criar um assistente de formulário com

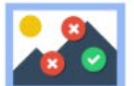

Encontre vários po... Crie muitos pontos de acesso para os usuários

Fonte: Autoria própria (2020).

No Moodle, todos os tipos de conteúdos estão disponíveis, basta inserir uma atividade e clicar no plugin H5P. Após escolher o recurso mais adequado, seja para uma atividade ou para uma apresentação de conteúdo interativa e realizar as configurações necessárias, o material já está pronto para acesso, como mostra a Figura 2. 
Figura 2 - Tela do Moodle para adicionar atividade ou conteúdo.

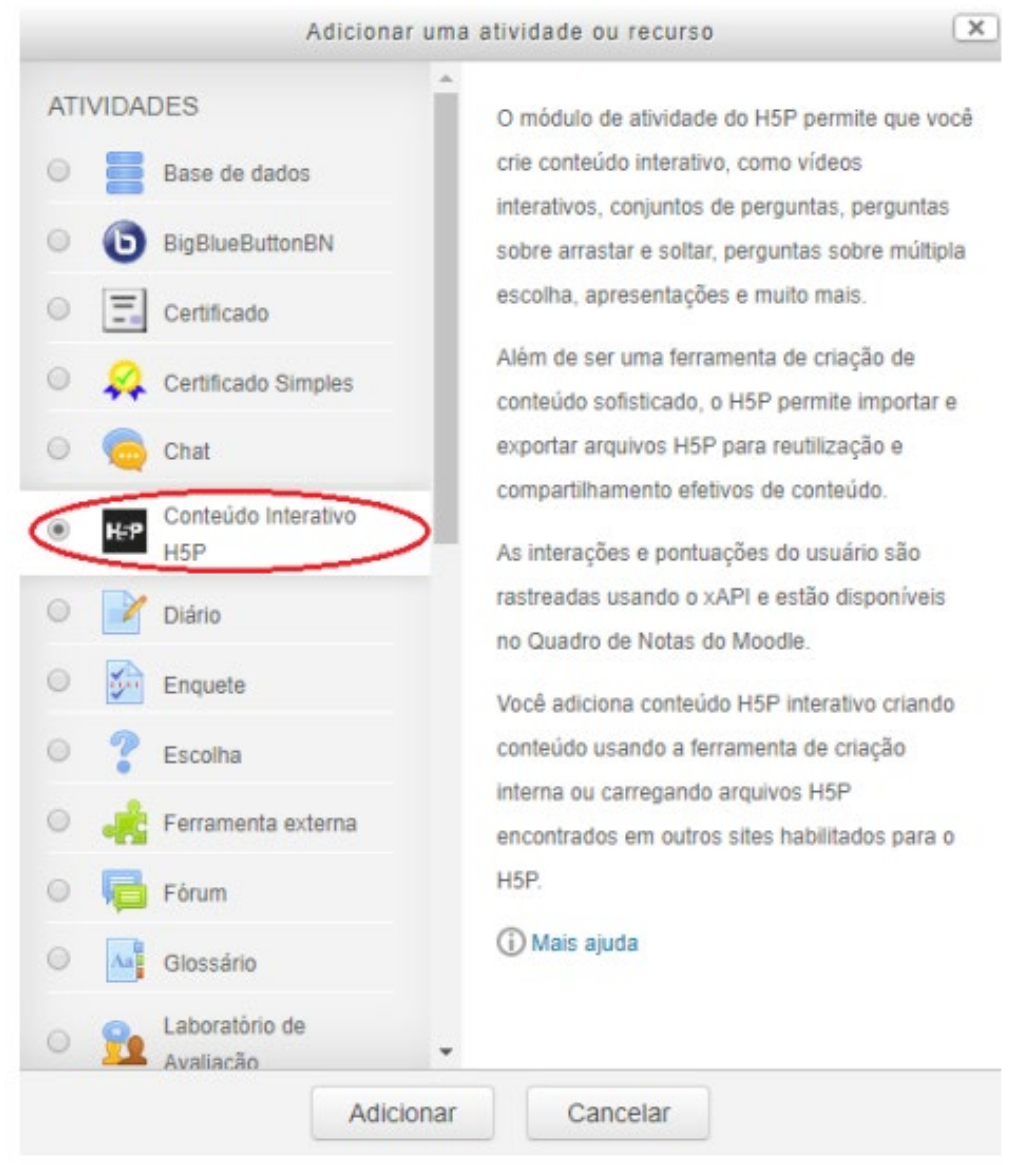

Fonte: Autoria própria (2020).

Ao elaborar conteúdo didático, o educador precisa conhecer o seu públicoalvo para entender qual a melhor forma de aprendizado para eles: se a forma auditiva, visual ou cinestésica. Isso é muito importante para obter um bom rendimento na aprendizagem.

A pesquisa é de natureza qualitativa, pois o propósito é verificar se um design diversificado do material didático que chega ao acadêmico pode melhorar o aprendizado. Segundo Minayo (2013), a pesquisa qualitativa se volta para o nível subjetivo e relacional da realidade social e é tratado por meio da história, do universo, dos significados, dos motivos, das crenças, dos valores e das atitudes dos atores sociais, diferente da quantitativa que enfatiza a objetividade, caracterizada pela coleta e análise dos dados.

\section{RESULTADOS E DISCUSSÃO}

Foram realizados diversos materiais para várias disciplinas do curso de História, seguem algumas figuras: 
Figura 3 - Famosos Historiadores e Teoria da História.

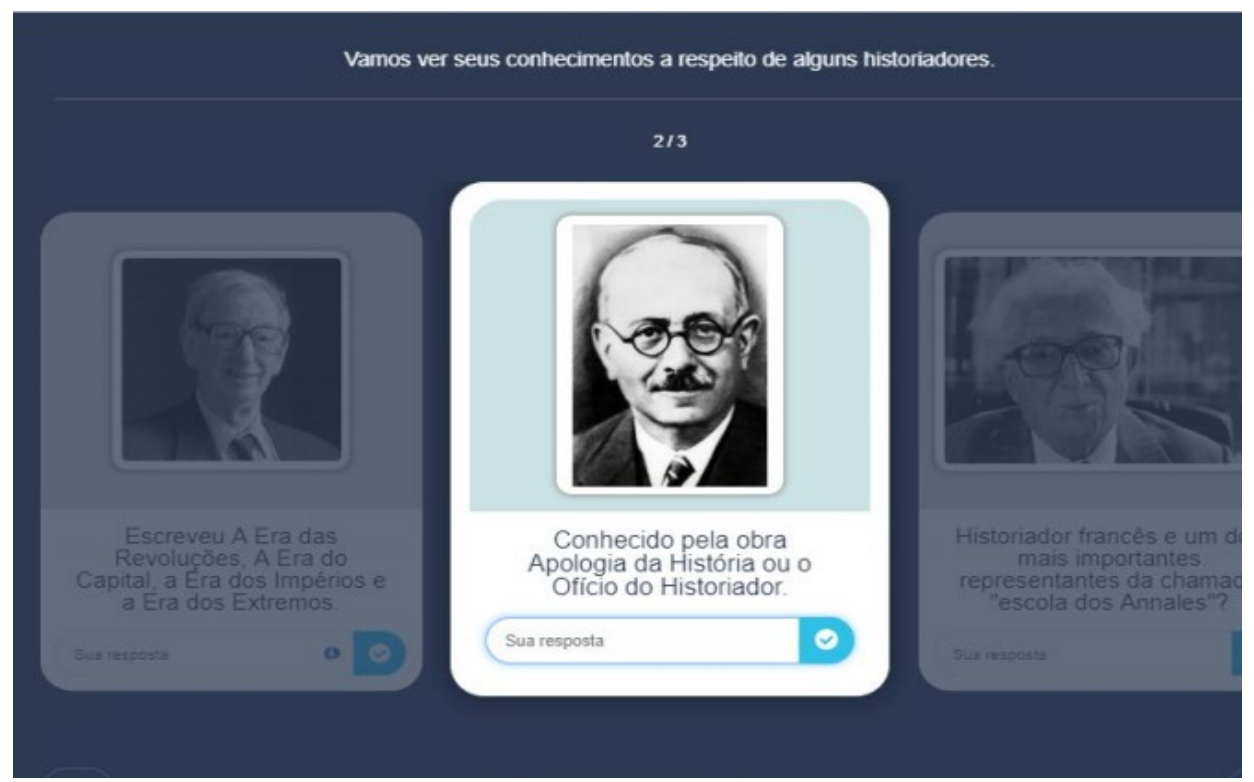

Fonte: Autoria própria (2020).

$\mathrm{Na}$ atividade acima, o aluno vê a imagem do historiador e responde a pergunta. Na questão, é possível avançar sem responder e voltar. A pontuação e a resposta correta podem aparecer ao final da tentativa, de acordo com a configuração. Uma característica das atividades elaboradas a partir do H5P é que ou elas possuem uma única tentativa ou são infinitas. Isso difere das configurações das atividades do próprio Moodle.

Figura 4 - Expansão do Território Brasileiro.

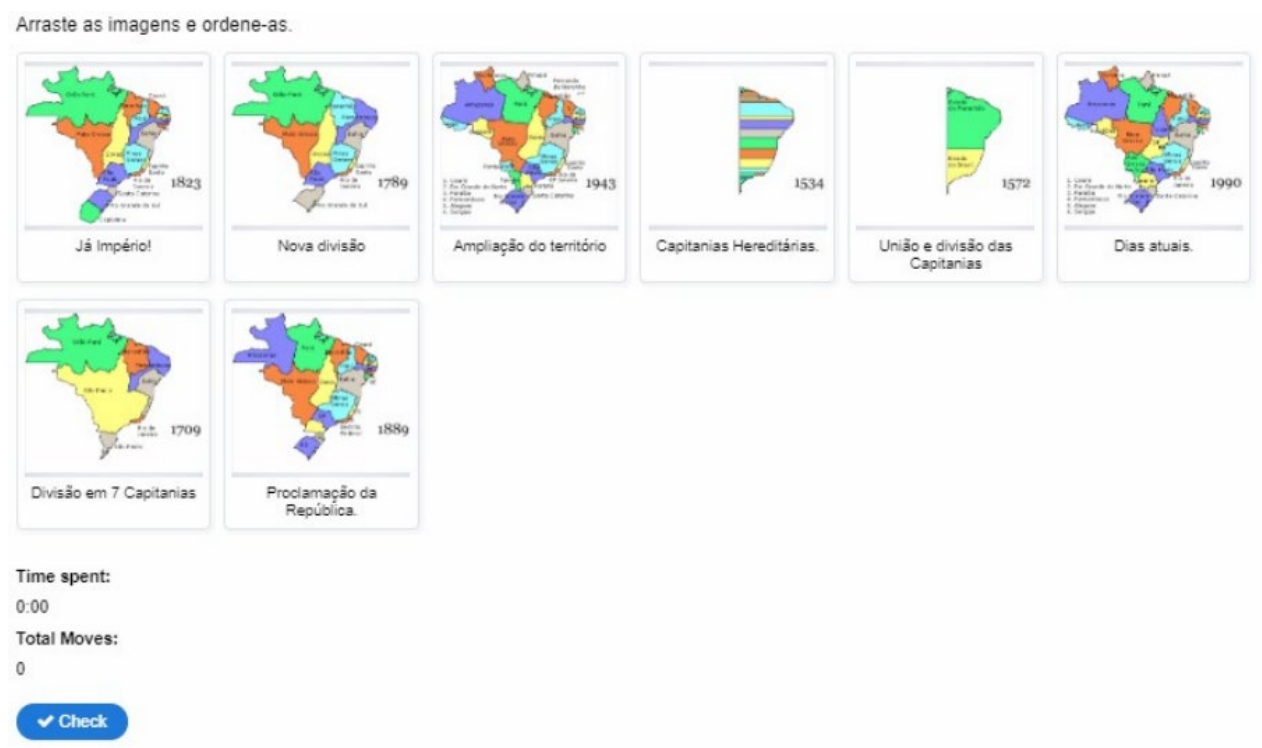

Fonte: Autoria própria (2020).

$\mathrm{Na}$ atividade que trabalha com a expansão do território brasileiro (Figura 4), o aluno deve arrastar as figuras de acordo com a cronologia correta. Há um cronômetro 
e um total de movimentos; ao final (de acordo com a configuração estabelecida), aparece a resposta correta.

As figuras foram retiradas da internet e na configuração da atividade há um local para inserir as informações sobre a fonte e dar os devidos créditos aos autores. Para elaborar este tipo de atividade, há a necessidade de dispor de figuras com as mesmas dimensões para elaborar a sequência.

O conteúdo da atividade proposta pode também ser trabalhado em cursos de Geografia e outros.

Figura 5 - Linha do tempo (Presidentes do Brasil).

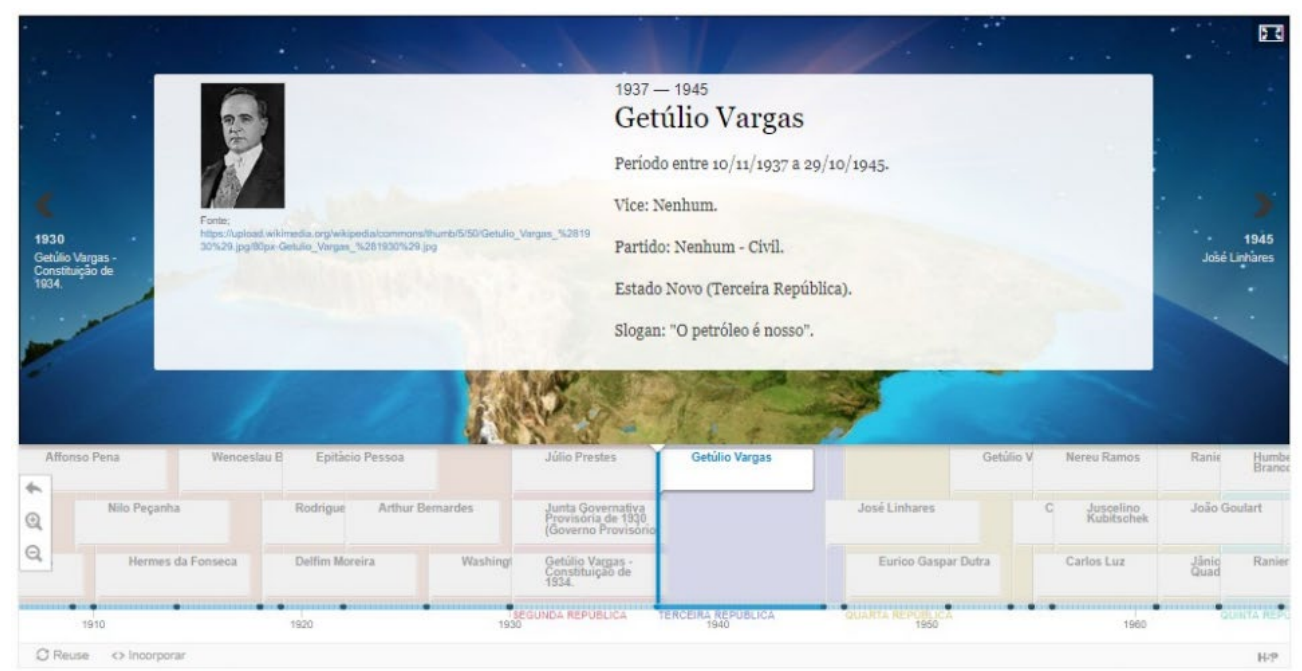

Fonte: Autoria própria (2020).

O modelo do conteúdo acima pode ser utilizado para todos os outros cursos e disciplinas. Neste exemplo, trabalhou-se com a história dos presidentes do Brasil. O aluno clica na seta da direita ou esquerda para avançar ou voltar. É possível inserir figuras, links de textos, vídeos e informações, como mostra a figura. Este modelo não é avaliativo, tem como intenção a apresentação do conteúdo de uma forma diferente.

Figura 6 - Escolas Históricas.

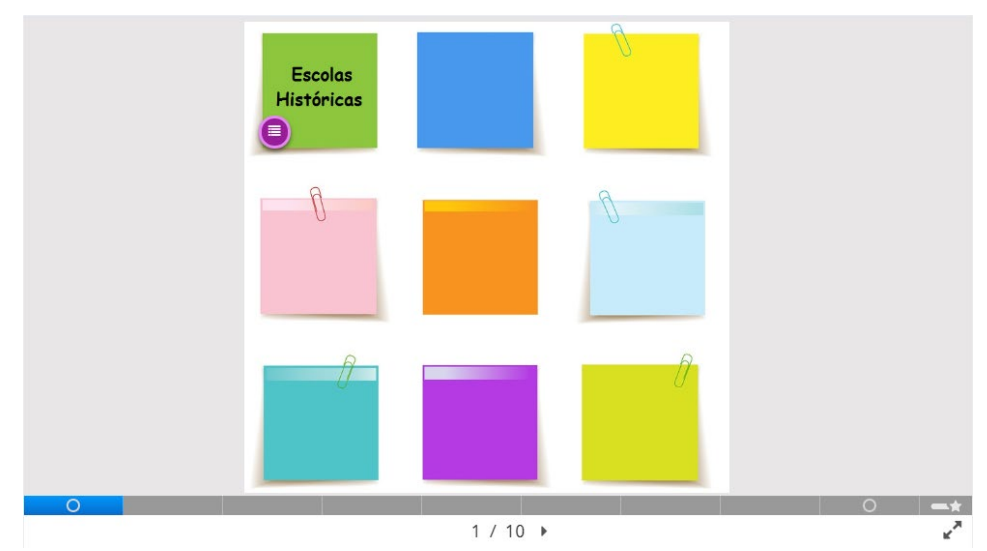

Fonte: Autoria própria (2020). 
Outra possibilidade que este recurso oferece é semelhante a uma apresentação de slides, mas aqui foi inserida algumas questões que os alunos teriam que realizar no momento da visualização. No primeiro slide, intitulado "Escolas Históricas", já se encontra a primeira interação, conforme figuras06 e 7 .

Figura 7 - Escolas Históricas (interação 1).

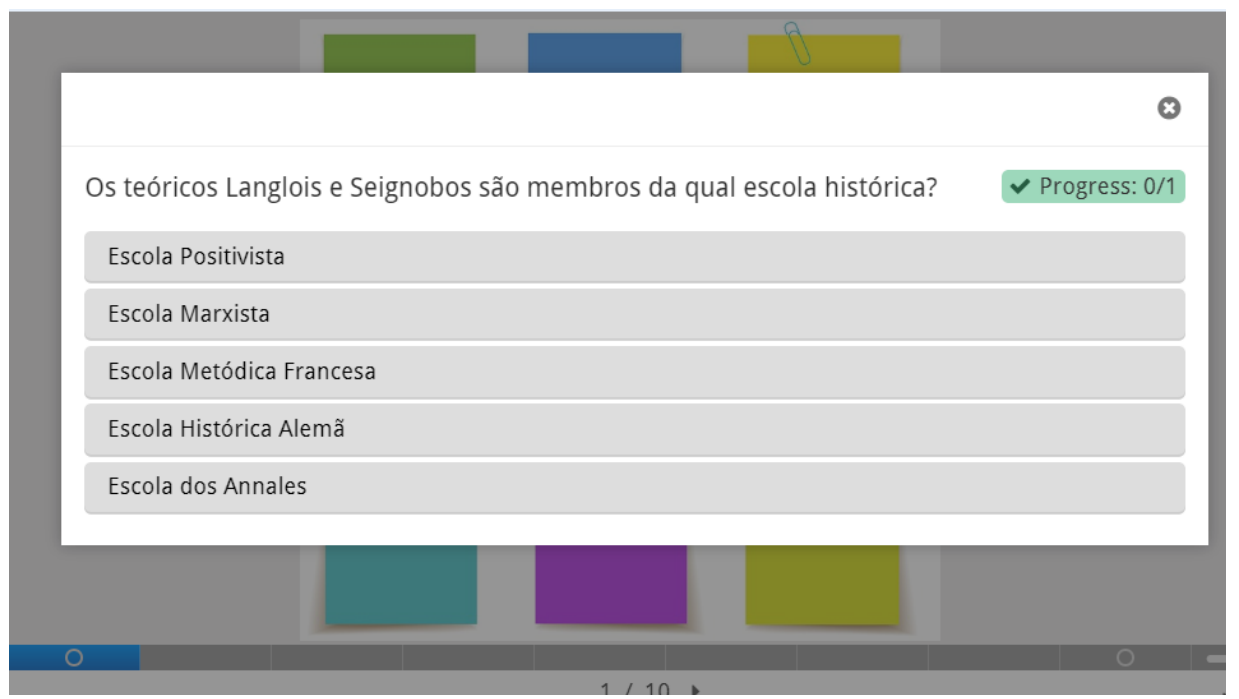

Fonte: Autoria própria (2020).

A configuração da atividade permite que seja atribuída pontuação para as questões marcadas corretamente e que as respostas erradas sejam indicadas logo na sequência (Figura 8).

Figura 8 - Escolas Históricas (interação 2).

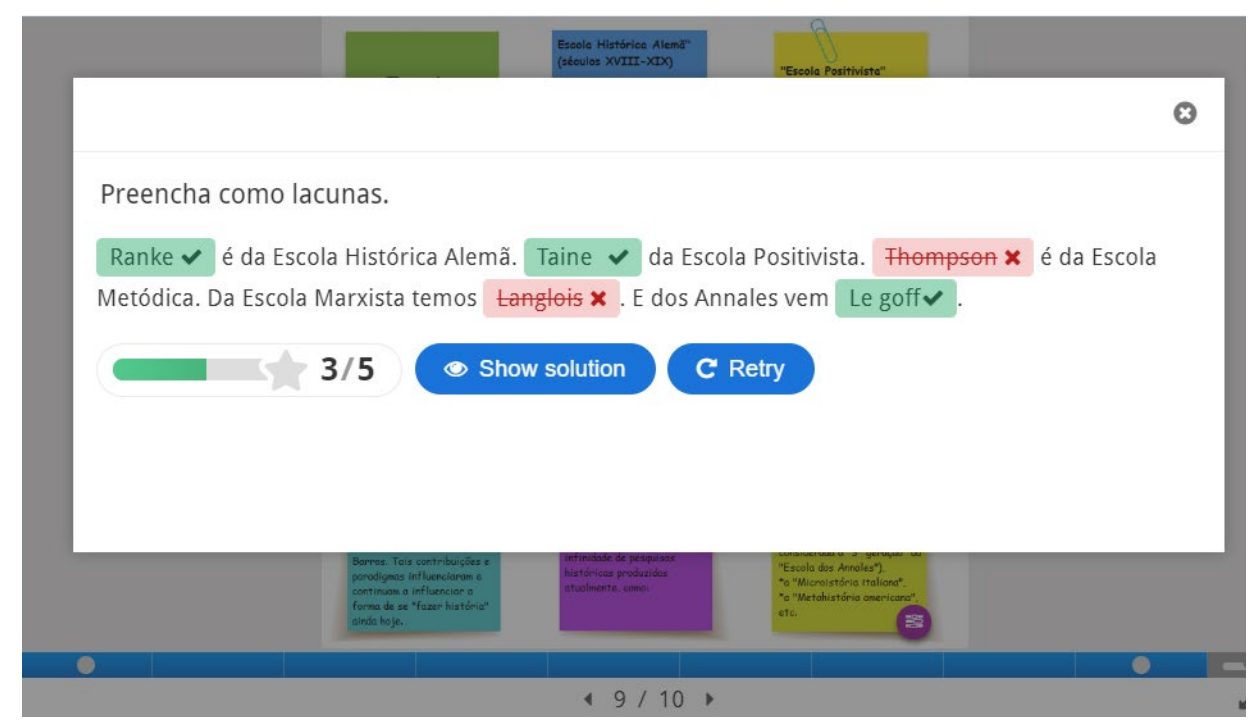

Fonte: Autoria própria (2020).

A pesquisa teve como público-alvo acadêmicos do curso de História do $3^{\circ}$ ano e com disciplinas semestrais. Foi desenvolvida no ano de 2019 com 34 estudantes. 
Esses alunos estudavam na modalidade à distância e responderam uma enquete disponibilizada no próprio AVA sobre as disciplinas que contemplavam recursos H5P, como História do Brasil e Teoria da História. Dos 34 respondentes, todos afirmaram que o conteúdo interativo possibilitou um maior entendimento sobre a matéria estudada e que a inserção de conteúdos como links, imagens e textos adicionais, como na Linha do Tempo, permitiu uma interpretação diferente do conhecimento já aprendido.

Os alunos revelaram que ainda não conheciam esses recursos e que nenhuma das disciplinas cursadas anteriormente utilizou essas ferramentas. $\mathrm{Na}$ última questão, onde eles poderiam dar sugestões, mais de $70 \%$ dos respondentes mencionaram que seria interessante se todos os professores utilizassem esses recursos, pois não fica tão monótono e "diminui" a quantidade de textos.

Conhecer a grande diversidade de recursos disponíveis no processo de ensino e aprendizagem é muito importante para não desmotivar os alunos. No cenário que estamos vivenciando, os professores são mediadores do conhecimento e se faz necessária uma abordagem mais dinâmica.

\section{CONSIDERAÇÕES FINAIS}

Um material bem organizado, bem elaborado, pode trazer muitos benefícios não só ao professor (que se satisfaz ao ver o resultado de um bom trabalho), mas também ao aluno, que atinge seu objetivo de aprender a partir de um material potencialmente mais significativo.

Os alunos, tanto da modalidade presencial como à distância, têm interesse em aprender e precisam mantê-lo durante todo o tempo do curso e o professor, nesse contexto, tem essa incumbência de instigar o aluno com materiais atrativos.

A cada instante surgem novos REA's, outros são remodelados, ressignificados; cabe ao professor estar em constante aprendizado para conhecer diferentes formas de ensinar para oferecer aos seus alunos diferentes maneiras de aprender. Outras formas de apresentar um mesmo conteúdo pode ser o diferencial de um professor.

Neste trabalho, apresentamos o H5P, que é um material potencialmente significativo para o ensino de História. Mostramos as possibilidades de apresentação de conteúdo e atividades a partir deste recurso com os métodos mais adequados, segundo o design instrucional para o ensino de História. Através da aplicação do material a estudantes do curso de Licenciatura em História de uma Universidade pública, observou-se que os alunos desconheciam tal abordagem ou ferramentas nas disciplinas já cursadas. Os alunos responderam que essa abordagem do conteúdo Ihes trouxe mais interesse pelas aulas e nos estudos em casa. 


\section{REFERÊNCIAS}

AUSUBEL, D.P.; NOVAK, J.D.; HANESIAN, H. Psicologia educacional. Rio de Janeiro, Interamericana. Tradução para português, de Eva Nick et al., da segunda edição de Educational psychology: a cognitive view.1980.

FILATRO, Andrea. Design instrucional na prática. São Paulo: Pearson Education no Brasil, 2008.

MATTAR, João. Games em educação: como os nativos digitais aprendem. São Paulo: Pearson Prentice Hall, 2010.

MINAYO, M. C. S. O desafio do conhecimento: pesquisa qualitativa em saúde. São Paulo: Hucitec, 2013.

TREVISANI, F. M.; BACICH, L.; TANZI NETO, A. Ensino híbrido: personalização e tecnologia na educação. Porto Alegre: Penso Editora LTDA, 2015.

\section{BIOGRAFIA DOS AUTORES}

FERNANDA BASSANI - Mestranda em Ensino de Ciência e Tecnologia (UTFPR - Ponta Grossa). Especialista em Educação a Distância e em Mídias na Educação. Professora Formadora e Tutora On-line em Cursos de Extensão. Designer Educacional no Núcleo de Tecnologia e Educação Aberta e a Distância - NUTEAD/UEPG.

HÉRCULES ALVES DE OLIVEIRA JUNIOR - Doutor em Física (UFPR). Professor Associado do Departamento de Matemática da Universidade Tecnológica Federal do Paraná. Professor Permanente do Mestrado em Ensino de Ciência e Tecnologia (UTFPR - Ponta Grossa). Avaliador de Cursos do INEP/MEC desde 2018. Editor Associado da Revista Brasileira de Ensino de Ciência e Tecnologia desde 2018.

ROMEU MIQUEIAS SZMOSKI - Doutor em Ciências - Física (UEPG). Atualmente é professor adjunto da Universidade Tecnológica Federal do Paraná e editor da Revista Brasileira de Física Tecnológica Aplicada. Também atua como professor permanente do Programa de Pós-Graduação em Ensino de Ciência e Tecnologia da UTFPR.

HERNANI BATISTA DA CRUZ - Doutorando em Ensino de Ciência e Tecnologia (UTFPR). Professor Colaborador da Universidade Estadual de Ponta Grossa. Entre as atividades desenvolvidas nos Colégios, pode-se destacar o desenvolvimento de projetos voltados para feiras de ciências utilizando Arduino e animações em 3D para reabilitação.

Data de recebimento: 01/09/2020

Data de aprovação: 23/10/2020 